\title{
Birmingham Medical Research Expeditionary Society 1977 Expedition: Signs and symptoms
}

\author{
R. F. FLETCHER \\ Ph.D., M.D., F.R.C.P. \\ Department of Diabetes and Endocrinology, Dudley Road Hospital, Birmingham B18 7QH
}

\section{Summary}

The BMRES group of 17 persons is described and details are given of the trek to $5400 \mathrm{~m}$. The research programme is outlined. Moderately severe acute mountain sickness (AMS) was observed in 5 subjects. All subjects were rated according to their symptoms related to AMS by interview, peer review and selfassessment, and the results compared.

\section{Introduction}

The Birmingham Medical Research Expeditionary Society (BMRES) was formed recently under the leadership of A. R. Bradwell. In October-November 1977 the society carried out its first expedition, a high altitude trek in western Nepal to investigate the genesis of acute mountain sickness (AMS). This and subsequent contributions to the symposium report the results of the research programme.

\section{Personnel}

The research group comprised 17 Caucasian males aged $22-50$ years. Ten were medically qualified, one was a medical student and the others were a photographer, a physicist, a chemist, an engineer, a supplier of mountain equipment and a lecturer in physical education. Only one had been to high altitude before but another was an experienced alpinist. About $50 \%$ had mountaineering experience but all were at least moderately athletic and apparently in good general health.

\section{Research programme}

This was designed to investigate 3 problems

1. Is it possible to predict who will be affected by AMS?

2. Are there any useful early warning signs or symptoms?

3. What biochemical and physiological changes precede and accompany AMS?

Before the expedition all members of the party were examined with pulmonary function tests, exercise tests, psychometric self-assessment and measurements of body composition including whole body potassium and nitrogen. Samples of blood and 24-hr urine collections were made. Most of these tests were repeated on return to Birmingham after the expedition.

During the trek, daily observations on all members of the party included a venous blood sample before rising, continuous 24-hr urine collections, diary recording of fluid intake, simple pulmonary function tests, weight and fat fold measurements, pulse rates at rest and after exercise, self recording of symptoms and mood, auscultation of lung bases and fundoscopy. Electrocardiograms were recorded at low and high altitude; some $24-\mathrm{hr}$ recordings were made.

\section{The trek}

The administrative arrangements for the trek were made by Sherpa Expeditions and Lufthansa. The trek followed a recognized tourist route with approximately normal schedules. Starting from the city of Pokhara in western Nepal the first 4 days of the trek covered a horizontal distance of about $65 \mathrm{~km}$ through the foothills to Tatopani. The altitude varied from 1000 to $3000 \mathrm{~m}$ and the weather was warm and humid. The second stage during days 5-7 was along the Kali Gandaki gorge for $48 \mathrm{~km}$, the altitude rising steadily from 1200 to $2700 \mathrm{~m}$ at Jomson. The weather was warm and dry. The third stage from days 8 to 12 were up an eastern side valley past Muktinath to the Thorang pass North of Annapurna. The distance was $23 \mathrm{~km}$ and the maximum altitude reached was $5400 \mathrm{~m}$. Day 9 was a rest day at $3500 \mathrm{~m}$. During days 10 and 11 the rate of ascent was $750 \mathrm{~m} /$ day. The highest camp, occupied at the end of day 11 was at $5000 \mathrm{~m}$. On day 12 all the party with 2 exceptions walked up to the pass and then returned to the high camp for a second night. The weather was dry and the walking was on paths free from snow. At the higher altitudes the night temperatures reached $-10^{\circ}$ to $-15^{\circ} \mathrm{C}$. Most of the scientific observations were terminated on days 12 to 15 .

\section{Diet}

Food intake was uncontrolled. The diet consisted of a mixture of imported dried or tinned food and locally purchased rice, vegetables, barley and flour. 


\section{General health}

There were no episodes of major illness except those due to altitude. During the first week of the trek 14 of the 17 members of the party had at least one attack of diarrhoea, often with some nausea. Of the 3 who escaped this, 2 were the only members taking prophylactic antibiotics (Streptotriad).

\section{Acute mountain sickness (AMS)}

As there is no specific diagnostic test for AMS, 3 methods of assessment of the effects of altitude were used to provide a clinical profile with which the results of investigations could be compared.

\section{Interview}

Various symptoms, signs, changes in behaviour and performance were noted by the medical officer during the expedition. Physical evidence was gained by auscultation of the lung bases and fundoscopy. During the return journey, all members of the party were subjected to a formal structured medical interview by 2 senior clinicians (A.D.W. and R.F.F.) to elicit symptoms thought to be due to altitude. This information was compiled to yield case descriptions (below) and also a ranking of all members according to the severity with which they were affected.

\section{Peer}

Members were invited to rank all the party, including themselves, according to their impressions as to how much they had been affected by altitude. Twelve members of the party felt able to co-operate in this. The resulting lists were consolidated in a simple arithmetical way to yield a single peer ranking.

\section{Self}

The daily assessment questionnaires were examined and the results obtained over $3000 \mathrm{~m}$ were consolidated, taking into account all symptoms and severity to give a rank order of severity of AMS.

\section{Results}

Apart from mild transient headache there were no symptoms below $3000 \mathrm{~m}$ which could be ascribed to altitude. Most of the manifestations were in the highest camp at $5000 \mathrm{~m}$.

\section{Cases}

Five members were considered to have definite AMS.

No. 1. On arrival at the high camp felt very ill, was confused and weak. Later found to be partly amnesic. He descended with an escort at once and recovered promptly.

No. 2 Markedly short of breath on exertion and had basal crepitations. Recovered overnight.
No. 3 Marked weakness; nausea and vomiting; short-tempered.

No. 4 Severe headache and photophobia; shorttempered.

No. 5 Oedema of face; acutely miserable with emotional lability.

In addition, 3 members noticed marked but transient ataxia. Ankle oedema was noted in 2 and another had transient basal crepitations.

Fundoscopy showed marked venous engorgement in all, but only 2 small retinal haemorrhages were seen. These did not correlate with AMS.

Twelve members noticed Cheyne-Stokes breathing but it was severe in only 3 . This also did not correlate with AMS.

Grading of symptoms are shown in Table 1.

TABLE 1. Incidence and severity of AMS. 'General' is an overall compilation of symptoms and signs. For 'torpor' see text

\begin{tabular}{lccc}
\hline & General & Headache & Torpor \\
Definite & 5 & 5 & 4 \\
Moderate & 4 & 6 & 3 \\
Mild & 5 & 6 & 1 \\
Trivial/None & 3 & 0 & 9
\end{tabular}

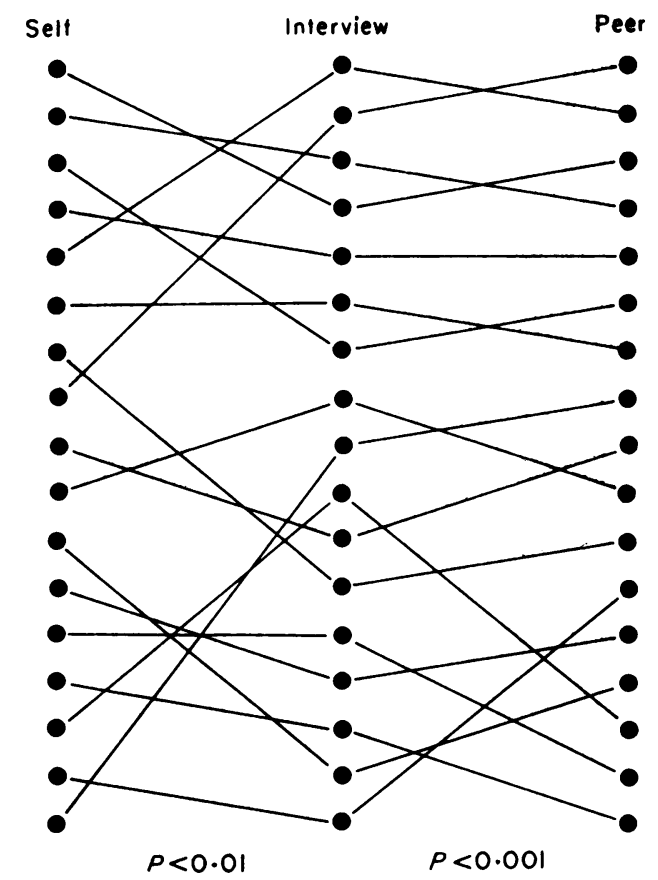

FIG. 1. Ranking of the members of the expedition in respect of the signs and symptoms of AMS, most severe at the top. The 3 systems of ranking are shown. Lines join individuals in the different ranks. Significance values from Kendall's rank order correlations. 
The term 'torpor' is used to describe a symptom of which many members complained. It was unfamiliar and difficult to describe but seemed to consist of a feeling of muscle weakness and mental indifference.

All symptoms remitted rapidly on descent.

\section{Ranking}

The 3 rank orders arrived at by the methods described are compared in Fig. 1. Each line joins the same individual in the different rankings.

The rank order correlation coefficients were calculated by the method of Kendall. As the 3 methods of assessment are not wholly independent, the coefficients should be interpreted with caution but it seems clear that the rankings are similar, particularly for the most severely affected individuals in the upper half of the lists. The interview ranking was adopted as the definitive reference for the subsequent correlation with the research results. The peer ranking correlated better with the interview ranking than did the self-assessment.

\section{Discussion}

DR C. S. Houston: I think that the statement about self-evaluation is absolutely right. You are not able to evaluate yourself.

DR J. G. Dickinson: Did you consider the difference between Cheyne-Stokes breathing at night and during the day?

DR R. F. Fletcher: I did not notice Cheyne-Stokes breathing during the day but others did. It was its occurrence at night which we recorded. It didn't correlate with the severity of other symptoms.

Mr M. P. WARD: Did you measure the length of apnoea?

DR Fletcher: No.

Mr WARD: My impression is that patients with Cheyne-Stokes respiration had longer periods of apnoea than did people at altitude. Do normal people, as they get older, have Cheyne-Stokes breathing at night?

DR FLETCHER: Yes they do.

MR WARD: Is that relevant to altitude?

DR J. S. MilledGE: Over the age of 40 years it is not abnormal to have Cheyne-Stokes breathing at night but whether it is more common for older people to have Cheyne-Stokes at altitude I don't know.

PROFESSOR O. WADE: You can see it quite often in young people also.

DR HousTon: There should be a distinction between what is known as Cheyne-Stokes breathing, which is a regular irregularity, and just plain disordered breathing. On Logan, using sleep encephalograms, ear oximeters and morning questionnaires we found a relationship between disordered breathing and symptoms. The greater the breathing disorder the greater the desaturation and the worse the hangover.

MR WARD: This would explain why you feel so bloody in the morning at altitude.

DR Fletcher: What we recorded as Cheyne-Stokes breathing was the classical crescendo type. It really caused more distress to tent mates who tended to wake up and lie there worrying whether the chap was actually going to start breathing again.

DR A. Adams: Did members of your party notice that on waking they saw a sort of darkness with little lights on it or things that looked like seagulls? We noticed this. It persisted for $40-60 \mathrm{sec}$ until you started moving around. We assumed that it was due to retinal hypoxia.

DR FLETCHER: I don't think that any of our party dared complain of this. Let's ask them now [no response].

ChaIRMan: This is obviously related to oestrogens!

Professor E. S. Williams: I have been on a number of trips including mixed parties and have never heard it mentioned.

A LADY PARTICIPANT: I would like to ask Dr Fletcher why he did not take any women on his expedition?

DR FleTCHER: None showed any interest in coming.

Professor Williams: Twenty years ago I took 2 mixed parties but the physiology of the male is difficult enough without having to sort out the menstrual and endocrine changes in the female. It is scientifically much too complicated - at least that's my excuse.

DR Houston: I agree. We take men and women on Logan. The problems encountered with mixed parties are not those related to altitude but are problems contemporary with our society. 